\title{
Two implementation models of workers' health education programs in Egypt: What works? What doesn't work?
}

\author{
Nahla G. Abdel-Tawab \\ Population Council \\ Norhan Bader \\ Elizabeth Tobey \\ Population Council \\ Aparna Jain \\ Population Council
}

Follow this and additional works at: https://knowledgecommons.popcouncil.org/departments_sbsr-rh

Part of the Community Health and Preventive Medicine Commons, Demography, Population, and Ecology Commons, Family, Life Course, and Society Commons, International Public Health Commons, Medicine and Health Commons, and the Women's Health Commons

How does access to this work benefit you? Let us know!

\section{Recommended Citation}

Abdel-Tawab, Nahla G., Norhan Bader, Elizabeth Tobey, and Aparna Jain. 2020. "Two implementation models of workers' health education programs in Egypt: What works? What doesn't work?" Research brief. Washington, DC: Population Council, The Evidence Project. 
Two Implementation Models of Workers' Health Education Programs in Egypt:

\section{What works? What doesn't work?}

Rationale

Objective

Research setting

Intervention target groups and communication approaches

Between 2008 and 2014, Egypt's fertility rate increased from 3.0 births per woman aged 15-49 to 3.5 , and unmet need for family planning (FP) increased from $10 \%$ to $12 \%$ among young people aged 18-35 [1,2]. Coupled with a decline in exposure to FP messages from $70 \%$ to $49 \%$ among this age group [1-3], this highlights the need for renewed attention to increasing demand for FP services among young people in Egypt.

The Evidence Project is evaluating two interventions aimed at increasing FP service demand among young people (aged 18-35) in Port Said and urban Souhag, two socioeconomically diverse governorates with young people who have varying FP use profiles and needs.

\section{PORT SAID}

Port Said is an urban governorate with a relatively high contraceptive prevalence rate (59\% of married women aged 15-49 use any FP method [1]) and with many factories that employ thousands of young men and women. More than half of factory workers employed in Port Said reside in rural neighboring governorates where FP information and services are less accessible than in Port Said.

The intervention began in 2017 and focused on male and female workers in five garment factories in the Investment Zone of Port Said. The Investment Zone includes nine factories of nearly 38,000 employees. Lotus factory, the largest of the 5 partner factories, has 13 subfactories that employs nearly 13,000 individuals. We trained 300 male and female factory workers as peer educators. Peer educators shared family planning/reproductive health (FP/RH) information face-to-face with their fellow workers and distributed communication materials containing $\mathrm{FP} / \mathrm{RH}$ information like posters, booklets, fliers, and the Ma3looma social media platform. ${ }^{a}$ Each peer educator was assigned 4045 factory workers to share $\mathrm{FP} / \mathrm{RH}$ messages during lunch/tea breaks and bus rides. ${ }^{\mathrm{b}}$ Factory workers who desired more information about FP methods were referred to the infirmary nurse who was trained in FP counseling as part of the intervention.
The intervention began in 2017 and focused on male and female job seekers (who had completed secondary school or were university graduates) in Souhag. We engaged job seekers in integrated $\mathrm{FP} / \mathrm{RH}$ livelihood workshops. Trained male and female peer educators $(n=80)$ offered trainings over five days (2.5 days for FP/RH and 2.5 days for livelihood skills). Two sessions were offered simultaneously-one for males and one for females. Each peer educator facilitated a session for 25-30 participants. Communication materials and information on Ma3looma social media platform were also introduced, as was done in Port Said. To date, 3,284 young men and women have participated in the integrated $\mathrm{FP} / \mathrm{RH}$ livelihood workshops. The workshops were organized by our implementing partner, Women's Association for Health Improvement (WAHI). 


\section{Project evaluation}

\section{Challenges in implemen- tation and evaluation}

\section{Project outcomes}

In Port Said, factory workers' knowledge and attitudes about $\mathrm{FP} / \mathrm{RH}$ were measured before (baseline) and six months into the intervention (endline) through phone interviews. Comparison factories where the intervention did not take place were identified and phone interviews were also conducted with factory workers in the comparison factories. Factory workers' phone numbers were shared by factory managers who obtained those numbers from a database of workers. The same factory workers were not interviewed at baseline and endline. A total of 1,766 and 1,239 factory workers from both the intervention and comparison factories completed baseline and endline phone interviews, respectively. Across all interviews, the response rate was approximately $40 \%$.

Peer educators faced time constraints to perform their responsibilities as peer educators due to their busy work schedules. According to factory managers, worker turn-over was high, especially among male workers who move to different factories to respond to purchase orders. Factory databases of workers' phone numbers were often inaccurate or outdated as factory workers often changed their SIM cards, and hence the response rate was low. Female factory workers were less likely to answer phone calls. While the male/female distribution in Port Said factories is $40 \% / 60 \%$, the male/female distribution in the phone interviews was $78 \% / 22 \%$.

Table 1 shows that in Port Said, there were few significant improvements in any of the key indicators, as shown from results of a differencein-differences (DiD) analysis comparing the intervention to the comparison group between baseline and endline. There was a significant increase only in the proportion of respondents who disagreed with the statement that FP methods can affect a woman's future fertility.

The data suggest that there was little impact of the intervention on workers' knowledge and attitudes. This may be a result of workers' high turnover, as some of the workers who have received $\mathrm{FP} / \mathrm{RH}$ messages may have moved to factories not included in the project, or to comparison group factories, and vice versa.

Workers' busy schedule and the low peer educator to worker ratio may have also resulted in limited exposure to the intervention.
In Souhag, young people's knowledge and attitudes about FP/RH were measured before (baseline) and three to six months after the workshops (endline) through phone interviews. A comparison group of young men and women of the same age who did not participate in the integrated workshop were identified in urban Souhag and interviewed by phone. Phone numbers of intervention participants were provided to Baseera by the implementing partner WAHI, while comparison group participants were reached through random digit dialing targeting young men and women aged 18-35. Across the interviews, the response rate was $90 \%$, with 1,477 participants interviewed at baseline and 1,124 at endline.

As peer education is a part-time, temporary position, peer educators often opted to take more stable, fulltime jobs resulting in high turnover. Young men were somewhat more difficult to recruit for the integrated $\mathrm{FP} / \mathrm{RH}$ livelihood workshops than young women. It is likely that some men were working part-time after school hours and hence were less available for this training. The male / female distribution in those workshops was $40 \% / 60 \%$. Fewer male than female participants answered the phone interview, at 30\% versus $70 \%$ respectively.

Table 2 presents results of a DiD analysis comparing the group that received the intervention to the comparison group between baseline and endline. At endline, participants who received the intervention were more likely to: (1) disagree with statements that FP methods have a negative impact on health and that FP can affect a woman's future fertility; (2) name optimal birth spacing interval as three or more years; (3) name three modern FP methods; (4) correctly identify the condom as a FP method that prevents STIs; and (5) be using FP or willing to use FP in the future.

The improvements in knowledge and attitudes that were noted in Souhag may be due to the fact that the intervention in Souhag was more intensive, the peer educator/participant ratio was high, and contact between peer educators and participants was repeated over a period of five days. Also, the phone interviews reached young people who participated in the intervention as phone numbers were obtained directly from them. 
TABLE 1: DIFFERENCE-IN-DIFFERENCES (DID) ${ }^{\dagger}$ ESTIMATES OF FACTORY WORKERS' KNOWLEDGE AND ATTITUDES ABOUT FP AT BASELINE AND ENDLINE IN INTERVENTION AND COMPARISON GROUP FACTORIES IN PORT SAID

\begin{tabular}{|c|c|c|c|c|c|c|c|}
\hline & \multicolumn{3}{|c|}{ Baseline } & \multicolumn{3}{|c|}{ Endline } & \multirow[b]{2}{*}{ DiD } \\
\hline & $\begin{array}{l}\text { Comparison } \\
(n=621)(\%)\end{array}$ & $\begin{array}{l}\text { Intervention } \\
(n=1,145)(\%)\end{array}$ & Difference & $\begin{array}{l}\text { Comparison } \\
(n=426)(\%)\end{array}$ & $\begin{array}{l}\text { Intervention } \\
(n=813)(\%)\end{array}$ & Difference & \\
\hline Ever heard of an FP method & 68.3 & 76.5 & $8.2 * *$ & 72.5 & 74.3 & 1.8 & -6.5 \\
\hline $\begin{array}{l}\text { Disagrees with: "FP methods have a negative } \\
\text { impact on health" }\end{array}$ & 50.2 & 47.2 & -3.0 & 46.7 & 47.5 & 0.8 & 3.8 \\
\hline $\begin{array}{l}\text { Disagrees with: "FP methods can affect } \\
\text { female fertility" }\end{array}$ & 43.6 & 41.0 & -2.7 & 38.0 & 43.7 & 5.6 & $8.3^{*}$ \\
\hline $\begin{array}{l}\text { Named optimal birth spacing interval as } 3 \text { or } \\
\text { more years }\end{array}$ & 40.9 & 40.6 & -0.3 & 43.2 & 47.1 & 3.9 & 4.2 \\
\hline Knows 3 modern FP methods & 27.7 & 34.5 & $6.8^{* *}$ & 31.2 & 38.9 & $7.6 * *$ & 0.8 \\
\hline Knows FP method that prevents STIs & 14.3 & 12.9 & -1.4 & 16.7 & 15.1 & -1.5 & -0.1 \\
\hline Using FP or willing to use FP in the future & 78.8 & 74.1 & $-4.7^{*}$ & 81.5 & 80.3 & -1.1 & 3.6 \\
\hline $\begin{array}{l}\text { Heard, read, or seen anything about FP in the } \\
\text { last } 6 \text { months }\end{array}$ & 16.9 & 16.2 & -0.7 & 22.8 & 17.2 & $-5.5^{*}$ & -4.9 \\
\hline
\end{tabular}

'Difference-in-differences estimations compare the difference in outcomes between the comparison and intervention at baseline to the difference in outcomes between the comparison and intervention at endline.

${ }^{*} p<0.05,{ }^{* *} p<0.01$

TABLE 2: DIFFERENCE-IN-DIFFERENCES (DID) ${ }^{\dagger}$ ESTIMATES OF YOUNG PEOPLE'S KNOWLEDGE AND ATTITUDES ABOUT FP AT BASELINE AND ENDLINE IN INTERVENTION AND COMPARISON GROUPS IN SOUHAG

\begin{tabular}{|c|c|c|c|c|c|c|c|}
\hline & \multicolumn{3}{|c|}{ Baseline } & \multicolumn{3}{|c|}{ Endline } & \multirow[b]{2}{*}{ Did } \\
\hline & $\begin{array}{l}\text { Comparison } \\
(n=699)(\%)\end{array}$ & $\begin{array}{l}\text { Intervention } \\
(n=778)(\%)\end{array}$ & Difference & $\begin{array}{l}\text { Comparison } \\
(n=383)(\%)\end{array}$ & $\begin{array}{l}\text { Intervention } \\
(n=741)(\%)\end{array}$ & Difference & \\
\hline Ever heard of an FP method & 83.1 & 83.3 & 0.2 & 83.3 & 96.1 & $12.8 * *$ & $12.6 * *$ \\
\hline $\begin{array}{l}\text { Disagrees with: "FP methods have a negative } \\
\text { impact on health" }\end{array}$ & 48.5 & 60.4 & $11.9 * *$ & 46.5 & 74.8 & $28.3^{* *}$ & $16.4 * *$ \\
\hline $\begin{array}{l}\text { Disagrees with: "FP methods can affect } \\
\text { female fertility" }\end{array}$ & 46.2 & 52.6 & $6.4^{*}$ & 48.6 & 73.5 & $25.0 * *$ & $18.6 * *$ \\
\hline $\begin{array}{l}\text { Named optimal birth spacing interval as } 3 \text { or } \\
\text { more years }\end{array}$ & 45.2 & 48.6 & 3.4 & 41.5 & 67.5 & $26.0^{* *}$ & $22.6 * *$ \\
\hline Knows 3 modern FP methods & 49.6 & 56.0 & $6.4^{* *}$ & 54.6 & 83.0 & $28.4^{* *}$ & $22.0 * *$ \\
\hline Knows FP method that prevents STIs & 13.0 & 18.0 & $5.0 *$ & 15.4 & 56.8 & $41.4 * *$ & $36.4 * *$ \\
\hline Using FP or willing to use FP in the future & 90.1 & 90.7 & 0.6 & 89.8 & 95.7 & $5.9 * *$ & $5.2 *$ \\
\hline $\begin{array}{l}\text { Heard, read, or seen anything about FP in the } \\
\text { last } 6 \text { months }\end{array}$ & 18.9 & 28.1 & $9.3^{* *}$ & 23.5 & 74.1 & $50.6 * *$ & $41.3^{* *}$ \\
\hline
\end{tabular}

${ }^{\dagger}$ Difference-in-differences estimations compare the difference in outcomes between the comparison and intervention at baseline to the difference in outcomes between the comparison and intervention at endline.

${ }^{*} \mathrm{p}<0.05,{ }^{* *} \mathrm{p}<0.01$

\section{PORT SAID}

\section{Conclusion}

Workers' well-being programs in factories need to take into consideration time constraints and the mobile nature of factory workers. Social media and other factory personnel (e.g., factory nurses) could support peer educators in communicating health messages to factory workers. Due to low responses, phone interviews using phone numbers collected from worker databases may not be suitable for evaluating interventions that target young people. Peer educators could collect phone numbers from coworkers with whom they communicated as part of the intervention.

\section{SOUHAG}

Integrating FP messages into livelihood training programs is an effective way of educating young men and women about FP/RH. However, the FP/ $\mathrm{RH}$ module may need to be expanded to include other health topics, such as smoking, obesity, and nutrition to make it more attractive to organizations implementing livelihood programs for youth. 
In this upcoming year, the intervention in Port Said will be enhanced to help peer educators communicate messages to more factory workers and reinforce face-to-face interactions through WhatsApp. Efforts will be made to increase the visibility of peer educators within factories by introducing them to their coworkers and giving them pins to wear saying "Peer Educator." While phone interviews will continue in Port Said to measure the effects of this "enhanced" intervention, phone numbers will be directly collected by peer educators from their coworkers and passed on to the evaluation team. Questions will be added to the questionnaire to find out the duration of participants' work in each factory as well as sources of information about FP. Additional insights from peer educators and participants will be gained through in-depth interviews and focus group discussions.
The intervention in Souhag will continue to train more young people. Efforts will be made to integrate the $\mathrm{FP} / \mathrm{RH}$ component into ongoing livelihood training programs that are implemented by other organizations (e.g., Ministry of Labor and Manpower, Agency for Development of Small and Micro Enterprise, Sawiris Foundation) in order to reach a wider base of young people in Souhag and nationwide. Phone interviews will continue to be conducted with participants of the training to monitor the intervention. Additional insights from peer educators and participants in the integrated $\mathrm{FP} / \mathrm{RH}$ livelihood trainings will be gained through in-depth interviews and focus group discussions in Souhag.

\section{Endnotes}

\section{References}

${ }^{a}$ Ma3looma website offers information about FP/RH to young people. Ma3looma FP is a Facebook page that offers information and answers questions about FP (https://www.facebook.com/ma3loma.tanzim/)

${ }^{b}$ The interventions in Port Said and Souhag were implemented in collaboration with Center for Development Services, Port Fouad Childhood and Motherhood Association, and Women's Association for Health Improvement (WAHI). The data collection for the evaluation was conducted by Baseera Center for Opinion Polls.

${ }^{1}$ Ministry of Health and Population (MOHP), El-Zanaty and Associates, and ICF International. 2015. Egypt Demographic and Health Survey 2014 [Dataset]. EGIR61FL.DTA. Cairo, Egypt and Rockville, Maryland, USA: Ministry of Health and Population and ICF International [Producers]. ICF [Distributor].

${ }^{2}$ El-Zanaty, Fatma and Ann Way. 2009. Egypt Demographic and Health Survey 2008 [Dataset]. EGIR5AFL.DTA. Cairo, Egypt: Ministry of Health, El-Zanaty and Associates, and Macro International [Producers]. ICF [Distributor], 2009.

${ }^{3}$ Abdel-Tawab, Nahla, Shadia Attia, Norhan Bader et al,. 2020 (forthcoming). “Fertility preferences and behaviors among younger cohorts in Egypt: Recent trends, correlates, and prospects for change." Cairo: The Evidence Project.

${ }^{4}$ Central Agency for Public Mobilization and Statistics (CAPMAS). 2018. Annual Employment Rates. Retrieved from https://www. capmas.gov.eg/Pages/IndicatorsPage.aspx?Ind_id=1117.

\section{THE EVIDENCE PROJECT}

Population Council 4301 Connecticut Ave, NW, Suite 280 Washington, DC 20008 evidenceproject@popcouncil.org

(c) 2020 The Population Council, Inc Photo credit for cover photo: (c) Port Fouad Association
The Evidence Project is made possible by the generous support of the American people through the United States Agency for International De-


Population Council and do not necessarily reflect the views of USAID or the United States Government.

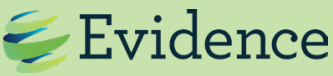

The Evidence Project uses implementation science-the strategic generation, translation, and use of evidence-to strengthen and scale up family planning and reproductive health programs to reduce unintended pregnancies worldwide. The Evidence Project is led by the Population Council.

Suggested Citation: Abdel-Tawab, Nahla, Norhan Bader, Elizabeth Tobey, and Aparna Jain. 2020. "Two implementation models of workers' health education programs in Egypt: What works? What doesn't work?" Research Brief. Washington DC: Population Council, The Evidence Project. 